\title{
Performance Evaluation of Two Reactive Routing Protocols for RWP Mobility Model with Different Speed
}

\author{
Neelam Singh ${ }^{1}$ and Laxmi Shrivastava ${ }^{2}$ \\ Department of Electronics, Madhav Institute of Technology \& Science \\ neelamsinghdohre@gmail.com,lselex@yahoo.com
}

\begin{abstract}
Wireless adhoc network are self creating self organizing and self administrating. The nodes within the network are free to move thus network do not rely on the preexisting infrastructure. Due to ease in deployment of mobile adhoc network wireless network are widely used. In the wireless network topology continuously changes according to the data packets to be sent at the destination path. With this so many best results in the wireless communication in this era wireless network over took wired network. In this paper we have compared the performance of two reactive MANET routing protocols AODV and DSR by using random way point mobility model. Both share similar On-Demand behavior, but the protocol's internal mechanism leads to significant performance difference. We have analyzed the performance of protocols by network load, mobility model and type of traffic (CBR). A detailed simulation has been carried out in QUALNET 6.1. The metrics used for performance analysis are Throughput, Average end-to-end Delay and Average jitter.
\end{abstract}

Keywords: MANET, AODV, DSR, QUALNET 6.1, CBR, Random way point mobility model

\section{Introduction}

As people moving towards the technical era, wireless communication systems are touching the acme of advancements by introducing the newer inventions and applications for its betterment. Nowadays, the user can enjoy the connectivity of network while moving from one place to another in any random manner. "The mobile node (MN) frequently changes their positions and authorize their self network [7]. Figure 1 shows the mobile Ad-hoc network.

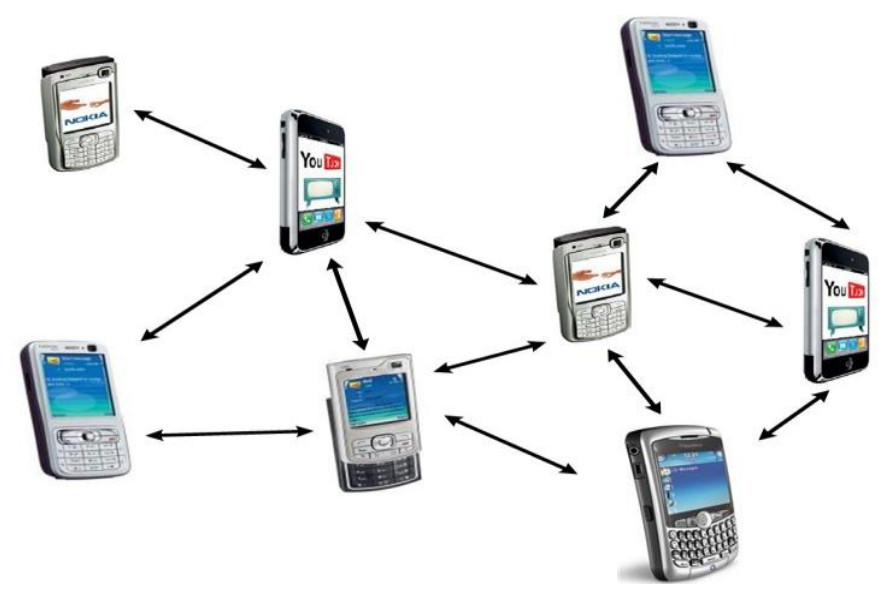

Figure 1. Mobile Ad-hoc Network 
MANET well known as short-lived networks, are autonomous system of mobile nodes forming network in the absence of any centralized support. Nodes can either enter or can leave the networks independently. Each and every node of MANET acts both as a routers and hosts to move ahead messages to other and intermediate nodes to move their data to destination [6]. Mostly, MANET is exploring in defense mechanism of military operations, various rescue operations, fire fighting mechanism, and remote sensors for weather, electronic fund transfer and various other daily activities such as taxi cab networks, virtual classrooms and even in voting system. Due to dynamic change in topology of nodes, the challenge in the mobile ad-hoc networks is its continuous routing of packets.

\section{Brief Description of AODV and DSR Routing Protocols-}

\section{Ad Hoc on-demand distance vector routing (AODV)}

The AODV routing protocol is pure reactive routing protocol for MANETs. It provides appropriate route on demand basis and its main aims is to reduce routing load [1]. Whenever a device initiates to send data, it first discovers the route by request/reply method and then only sends the data [3]. AODV routing protocol uses some of control messages namely route request (RREQ), Route Reply (RREP) and Route Error (RERR) for data delivery. Route information is kept by forwarding data nodes which came from DSDV and this is biggest advantage of AODV[2]. The main Advantage of the AODV it reduces control traffic messages overhead at the cost of increased latency in finding new routes[9].

\section{Dynamic source routing (DSR)}

DSR is a simple and efficient routing protocol designed especially for use in multi hop wireless Ad-Hoc network of mobile nodes. DSR routing protocol is also a reactive routing protocol. This routing protocol is composed of two mechanisms, route discovery and route maintenance. These mechanisms works together to allow nodes to discover and maintain routes. DSR uses aggressive caching to reduce the frequency and propagation of route discoveries[5]. DSR also used a route record to save the routes in the source nodes. This routing protocol doesn't need to consistently update its routing table like AODV.

\section{Simulation Environment-}

This simulation is performed using Qualnet 6.1 simulator. It provide mobility element; Speed, Start time movement, area of movement, the pause time of mobile node and their corresponding probability type (e.g., uniform, exponential, etc.).

\section{Simulation Parameter}

\section{Performance Metrics}

Some important performance metrics can be evaluated:-

Average end to end delay - The difference in the calculation while transmitting, packets forwarding time and receiving time is average end to end delay. This delay is generally due to route discovery, re-transmission delay and queuing propagation[8].

$$
D=\left(T_{R}-T_{S}\right)
$$


Throughput - Throughput is the successful packets delivered to the destination over communication channel. This data packet may be delivered over a physical or logical link or passed through a certain network load. Throughput is measured in bits/sec.

$$
\text { Throughput }=\frac{\text { Total packet received }}{\text { total packet sent }}
$$

Average jitter - Jitter is variation in the packet arrival to the destination. If jitter. is low better is the performance of routing protocol. It is caused due to congestion, topology change etc., in the network.

\section{Simulation Analysis}

The simulation results are shown in the form of graph.

\begin{tabular}{|c|c|}
\hline Parameters & Value \\
\hline Simulator & QualNet 6.1 \\
\hline Terrain Area $\left(\mathrm{m}^{*} \mathrm{~m}\right)$ & $1500 * 1500$ \\
\hline Simulation time & $150 \mathrm{sec}$ \\
\hline Routing Protocols & AODV, DSR \\
\hline No. of nodes & 50 \\
\hline Speed & $10,20,30,40,50,60$ \\
\hline Antenna & Omnidirectional \\
\hline Traffic type & CBR \\
\hline Mobility model & Random Way Point \\
\hline MAC layer & $802.11 \mathrm{~b}$ \\
\hline
\end{tabular}

Average end to end delay- It is evident from the result that AODV routing protocol has minimum delay for both node in comparison to both node of DSR .AODV Routing protocols gives better result for delay in comparison to DSR. On comparing nodes $(5,49)$ of AODV, node 5 has minimum value of delay because distance from source to destination is less and for node 49 there is maximum value of delay because distance between source to destination is faraway. Likewise on comparing the nodes of DSR node 49 give maximum value of delay to that of the node 5 due to distance.

Average jitter - In this performance metrics, we get the better result in AODV than DSR for both node 5 and 49 because there is minimum delay in AODV. Delay in the delivery of packet from source to destination is called jitter. And the minimum delay in jitter is best suited for our result. Our graph shows, AODV has minimum value of jitter with the different speed because it make a route between nodes only when it is required by source route. Whereas in DSR give maximum value of jitter because the sender of packet determines the whole path from the source to destination nodes. 


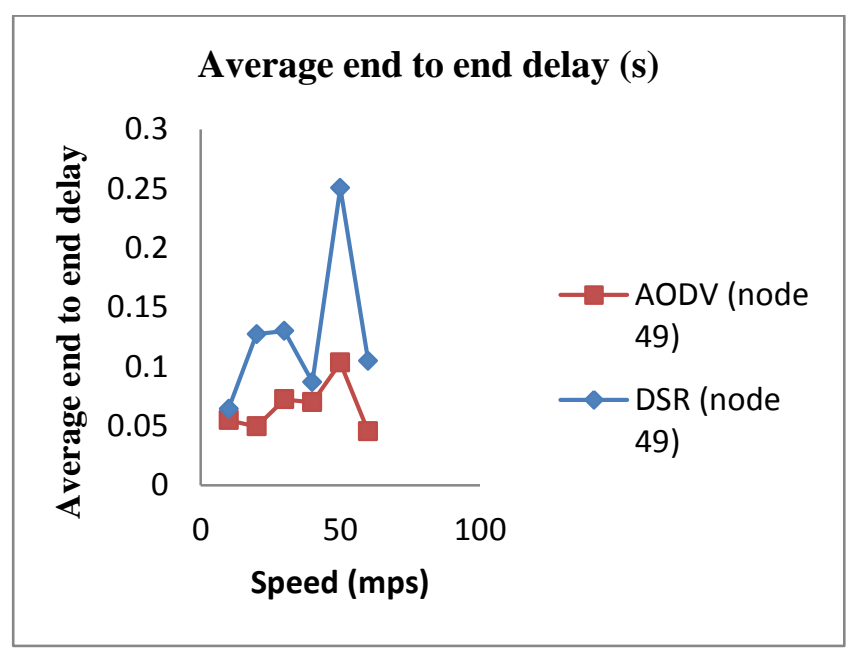

Figure (a). Average end to end Delay for AODV and DSR (node 4)

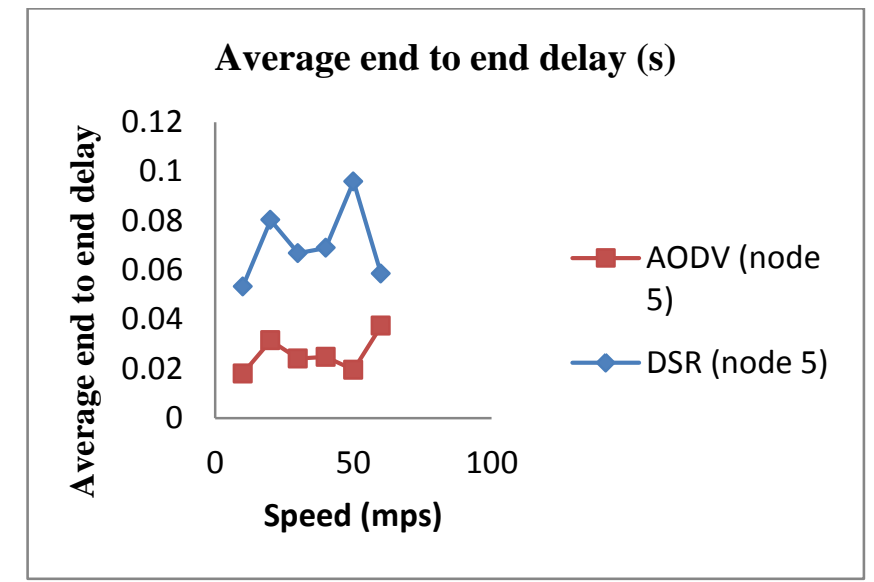

Figure (b). Average end to end delay for AODV and DSR (Node 5)

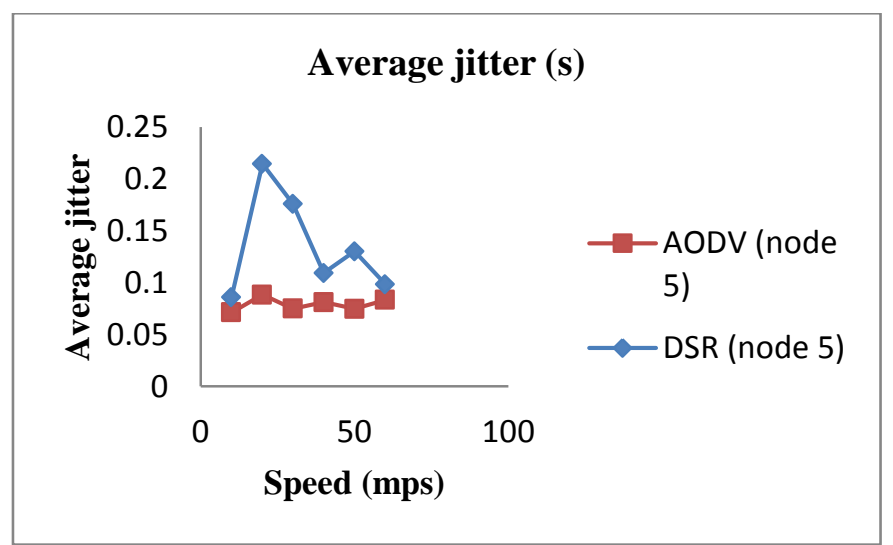

Figure (c). Average Jitter for AODV and DSR (Node 5) 


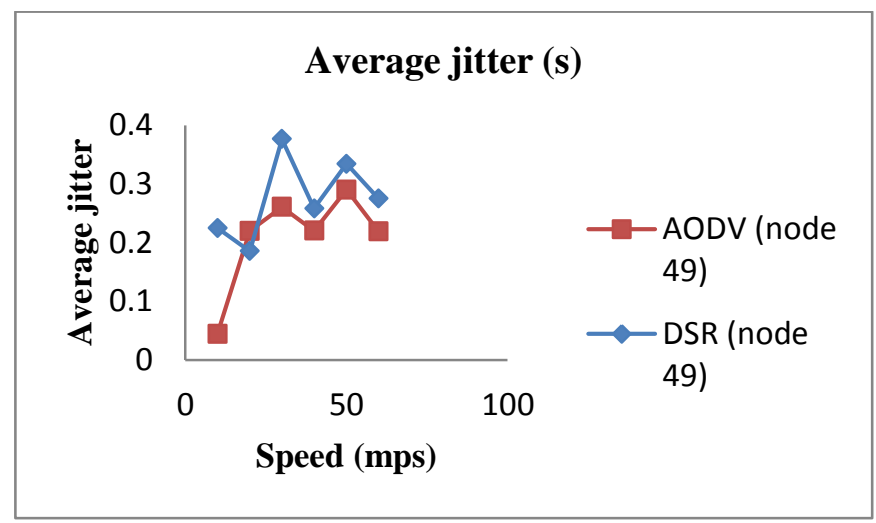

Figure (d). Average Jitter for AODV and DSR (Node 49)

Throughput - It is evident from the results that throughput of AODV and DSR has some marginal difference for node no. 5 (destination node) because the source node and destination node are closely joint. But for the node no. 49, AODV and DSR has much difference in throughput value because the node no. 49 are locate so far from the source node. Here also AODV gives better result in comparison to DSR.

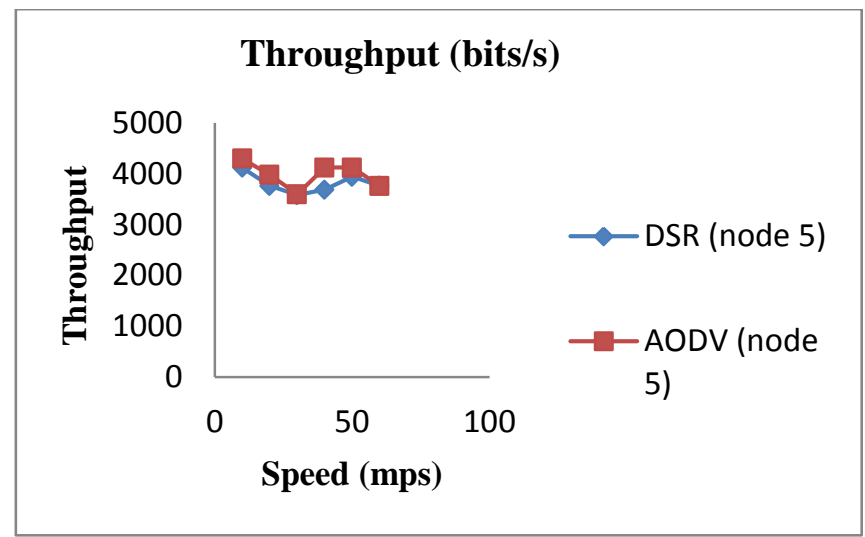

Figure (e). Throughput for AODV and DSR (Node 5)



Figure (e). Throughput for AODV and DSR (Node 49) 


\section{Conclusion}

This paper discusses the performance comparison of nodes of AODV and DSR routing protocols based on the simulation result Qualnet5.2 for the different performance metrics used for the performance comparison of protocols. In this study, it has been observed that AODV achieve the highest throughput and least end-to-end delay, jitter when compared to DSR routing protocol with the different speed. And it is also observed by the graph that distance between the source to destination of nodes also effect our results. We get better result when the nodes has minimum distance.

\section{References}

[1] N. Kasim, F. Said and H. Aghvami, "Mobile adhoc networks simulation using Routing protocols for performance comparisons", Proceedings of the world congress on Engineering 2008 vol I WCE 2008, London, UK, (2008) July 2-4.

[2] M. Shaffatul Islam, A. Riaz and M. Tarique, "Performance analysis of routing protocols of mobile Adhoc Networks for VOIP applications", Journal of selected areas in Telecommunications (JSAT), (2012) June.

[3] S. Naseer, S. A. Hussain, I. Raza, S. R. Chaudry, J. S. Mirza and M. H. Raza, "Simulation and Performance Analysis using Multimedia Traffic", Journal of Basic. Appl. sci. Res., vol. 2, no. 10, (2012), pp. 9925-9930.

[4] G. Jayakumar and G. Ganapathi "Reference Point Group Mobility and Random Waypoint Models in Performance Evaluation of MANET Routing Protocols", Journal of Computer Systems, Networks and Communications, Article ID 860364, vol. 2008, (2008).

[5] R. Kumar Gujral and M. Singh, "Performance Analysis of Ad hoc Routing Protocols for Voice Communication Support over Hybrid MANETs" International Journal of Computer Applications, (0975 - 8887), vol. 22, no. 3, (2011) May.

[6] S. Mahajan and V. Chopra " Performance Evaluation of MANET Routing Protocols with Scalability using QoS Metrics of VOIP Applications", International Journal of Advanced Research in Computer Science and Software Engineering, vol. 3, no. 2, (2013) February.

[7] A. Kumar and P. Mittal, "A Comparative Study of AODV \& DSR Routing Protocols in Mobile Ad-Hoc Networks", International Journal of Advanced Research in Computer Science and Software Engineering, vol. 3, no. 5, (2013) May.

[8] S. Shrivastava, L. Shrivastava and S. Singh Bhadauria, "Throughput and Delay Analysis of Wireless Mobile Adhoc Network with Different Transmission Power by Varying Antenna Height”, IJCSN, vol. 4, no. 2, (2014) December, pp. 59-63.

[9] P. Kumar Maurya, G. Sharma, V. Sahu, A. Roberts and M. Srivastava "An overview of AODV Routing Protocol", International Journal of Modern Engineering Research, vol. 2, no. 3, (2012) May-June.

[10] L Shrivastava, G. S. Tomar and F. Wang, "An Advanced Congestion Adaptive Routing Mechanism”, IEEE Fourth CICSyN, (2012), pp. 153-157.

[11] L. Shrivastava, S. S. Bhadauria and G. S. Tomar, "Performance Evaluation of Routing Protocols in MANET with different traffic loads", IEEE International Conference on Communication Systems and Network Technologies CSNT, (2011), pp. 13-16.

[12] L. Shrivastava, S. S. Bhadauria and G. S. Tomar, "Influence of Traffic Load on the performance of AODV, DSR and DSDV in MANET", International Journal of Communication Systems and Network Technologies, vol. 1, no. 1, (2013) April, pp. 22-34.

[13] G. S. Tomar, T. Sharma, D. Bhattacharyya and T. H. Kim, "Performance Comparison of AODV, DSR and DSDV under Various Network Conditions: A Survey", Proceedings of the 2011 International Conference on Ubiquitous Computing and Multimedia Applications, Doi:10.1109/UCMA.2011.9, (2011), pp. 3-7. 